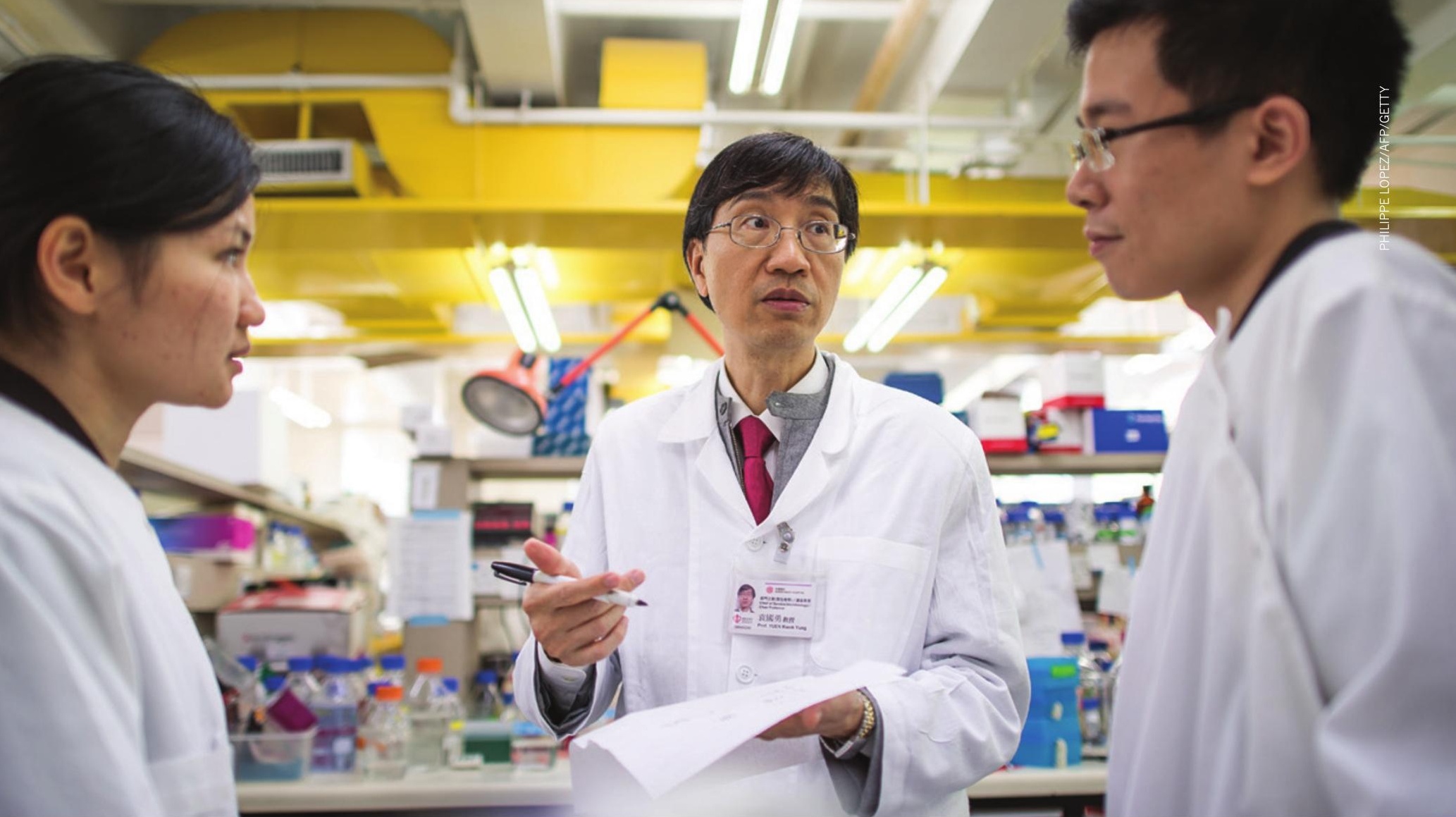

Hong Kong-based Yuen Kwok-Yung, who identified the cause of SARS, says collaboration between scientists of different perspectives leads to novel breakthroughs.

\title{
ALLIANCES FOR SCIENTIFIC SUCCESS
}

The diverse histories of China's cities strongly influence their collaboration patterns.

\section{BY HEPENG JIA}

$\mathrm{X}$ u Aimin knew that collaborating represented his best chance for success his quest at Hong Kong University (HKU) to identify the relationship between obesity and the glucose-regulating hormone adiponectin.

Connecting with colleagues in Saudi Arabia and Korea, he formed a team that revealed something unexpected. While obesity is a consequence of metabolic dysfunction, it is also exacerbated by it, because the expression of adiponectin is reduced. Altering this activity may represent a new strategy for the treatment of obesity-related disorders, their study, published in Nature Communications, suggests.

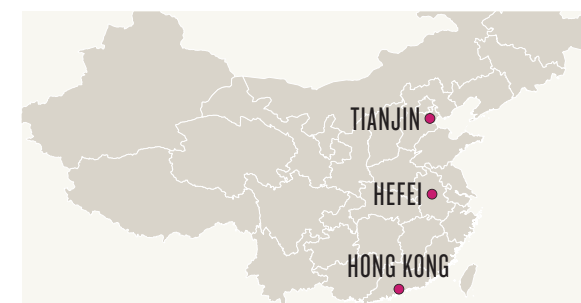

The findings came about through the team's combined knowledge and resource base, drawing on the Korean researchers' physiology expertise, the HKU lab's excellence in biology and unique animal models, and the Saudi Arabian lab's clinical samples.

"Hong Kong is a relatively small place," says $\mathrm{Xu}$, a professor in the university's department of medicine. "Collaboration with [Chinese] mainland and overseas institutes is the best way to maximize the economic and societal impacts of our research."

Xu's first-hand experience echoes what large scale studies show about science in the twentyfirst century: research resulting from collaborations is more frequently cited, especially papers with international co-authors.

In the Nature Index, three Chinese cities stand out for their collaborative orientation: Hong Kong, Hefei and Tianjin.

The focuses of their collaborations differ, all bring great reward. While Hong Kong and Hefei institutions have formed a record number of partnerships with their international peers (see 'Hong Kong's hotspots'), Tianjin scientists have focused on forging local links (see 'Close ties').

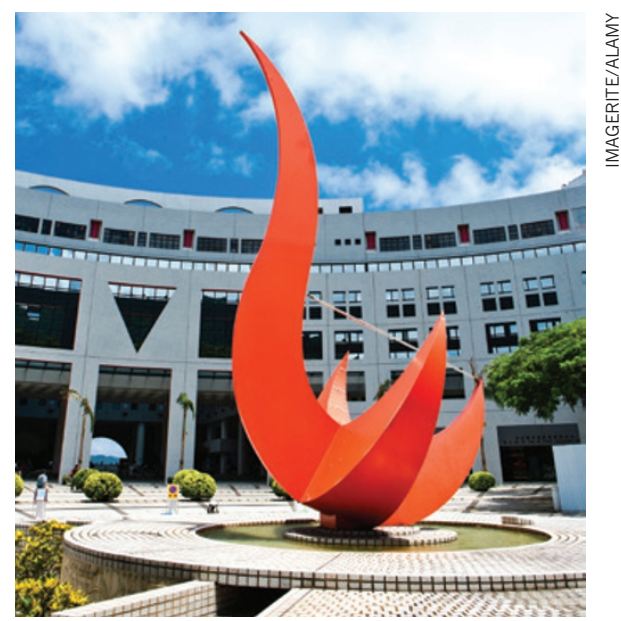

A sculptural sundial at HKUST represents early human invention, an inspiration for scientists.

Exploring the roots of these patterns reveals the importance of history in shaping regional strengths.

As Wu Yishan, vice president of the Chinese Academy of Science and Technology for Development, puts it: "With the joint forces of historical tradition, research capacity, local 
policies and personal links, Chinese regions have formed different preferences in research collaborations."

\section{HONG KONG \\ WFC rank China: 7 \\ A AC: 600}

The index shows that Hong Kong's collaborations are firmly entrenched with, but certainly not limited to, mainland China, the United States and Europe. For example, the two leading international collaborators for the Hong Kong University of Science and Technology (HKUST) are the National University of Singapore and Singapore's Agency for Science, Technology and Research. HKU's most frequent overseas collaborator is Taiwan's National Tsing Hua University (see 'Hong Kong's hotspots').

The collaborative atmosphere in Hong Kong appears to be fostered by funding policies. The region's local agencies support a large number of collaborative and joint funding schemes with other bodies at home and overseas.

An example is the HKU-Pasteur Research Centre, which was established to tackle emerging infectious diseases in China and elsewhere in Asia. Yuen Kwok-Yung, an HKU microbiologist who is renowned for tracing the human SARS (severe acute respiratory syndrome) coronavirus to Chinese horseshoe bats, was appointed its first co-director. Yuen then went on to help launch the HKU AIDS Institute in collaboration with the Aaron Diamond AIDS Research Center, an affiliate of Rockefeller University in New York. "Scientists from different cultures and ethnicities have very different and novel perspectives for looking at a scientific question and provide varied approaches to find the solution," Yuen says.

\section{HEFEI \\ त WFC rank China: 5 \\ A AC: 696}

Like Hong Kong, Hefei, capital of the Chinese mainland hinterland province of Anhui, has a limited number of research institutions in the index. One of these, the University of Science and Technology of China (USTC), is the driving force behind the city's collaborations. USTC's WFC between 2012 and 2014 was 517, more than six times that of the second player, the Hefei Institutes of Physical Science, which is affiliated with the Chinese Academy of Sciences (CAS).

History and tradition help explain USTC's unique role. Founded by CAS, the university moved from Beijing to Hefei in 1969 during the Cultural Revolution. Following the opening

\section{HONG KONG'S HOTSPOTS}

While collaborations with the United States dominate the top five partnerships for Hong Kong's leading institutions, each has a particular regional focus for their remaining partners.
140

\section{REACHING OUT}

The University of Hong Kong has many

partnerships in the

United States and

western Europe.

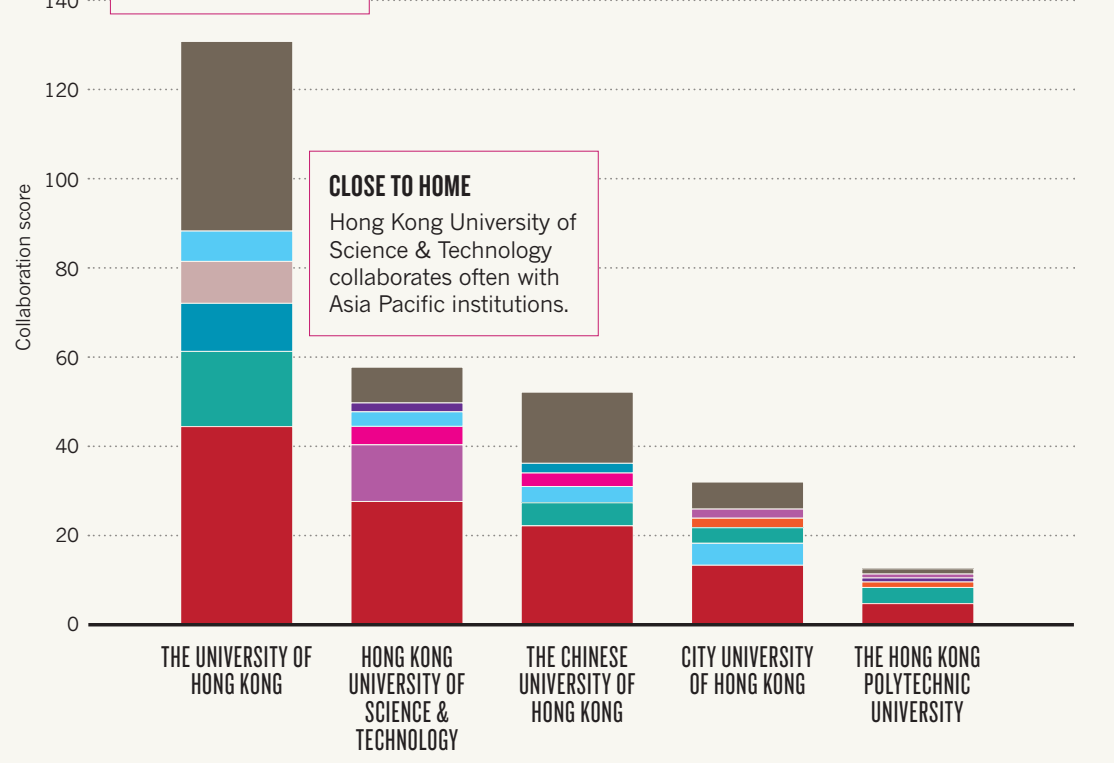

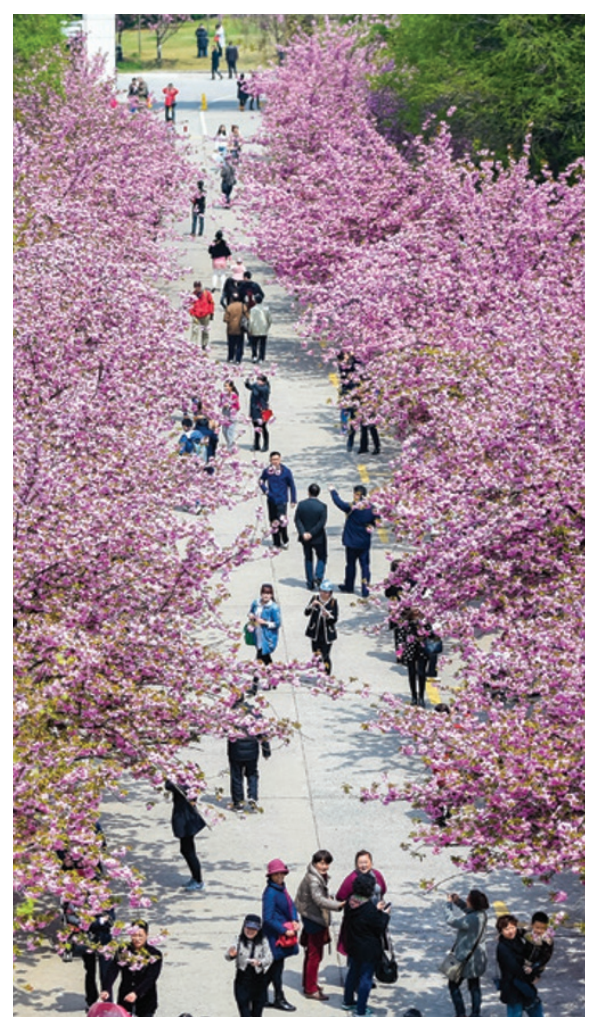

Hefei's USTC campus provides a highly supportive environment for collaborative research.

up of China, a large number of USTC alumni went to overseas institutions, temporarily or permanently. This, combined with a dearth of other local institutes to work with, has pushed the university towards international collaborations for cutting-edge research, particularly in physics and chemistry.

A USTC physics professor, Guo Guoping, says that he and colleagues regularly seek collaborations to promote theoretical developments based on their experimental results. "International partners are crucial to explore our frontier studies," he says. A good example is a study Guo recently co-authored in Physics Review Letters with scientists from the United States and Japan which explores the application of graphene in quantum
"Support for collaboration is reflected in Hong Kong's funding policies." communication.

USTC is jointly sponsored by CAS and the Ministry of Education. This historic link has contributed to the university's widespread collaborations with CAS institutes. In 2014 CAS was USTC's largest partner, earning it a collaboration score of 136.43 . The collaboration score is an indicator of an institution's collaboration in terms of co-authorship of articles in the 68 high-impact journals covered by the index.

Both Guo and Yuen at HKU argue that while policy support is important, science rather than money drives collaboration. 
IT TAKES TWO

International and domestic collaboration scores of Tianjin's top 10 collaborating institutions.
International collaboration score

Domestic collaboration score

NANKAI
UNIVERSITY
TIANJIN
UNIVERSITY
TIANJIN
MEDICAL UNIVERSITY
TIANJIN NORMAL
UNIVERSITY
TIANJIN INSTITUTE OF INDUSTRIAL
BIOTECHNOLGGY, CAS
TIANJIN MEDICAL UNIVERSITY
CANCER INSTITUTE \& HOSPITAL
TIANJIN POLYTECHNIC
UNIVERSITY
TIANJIN UNIVERSITY
OF TECHNOLOGY
HEBEI UNIVERSITY
OF TECHNOLOGY
TIANJIN UNION
MEDICINE CENTRE

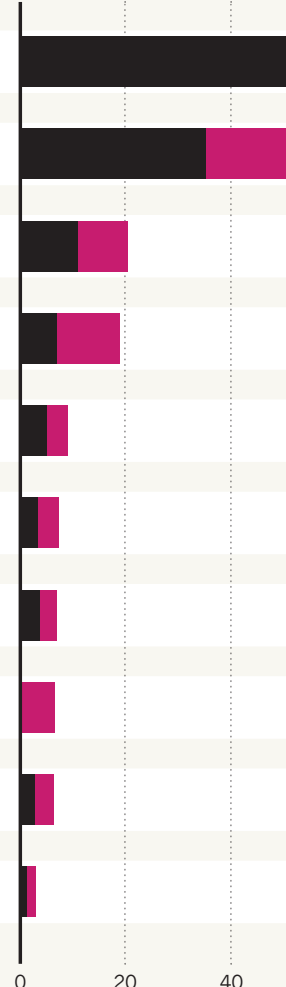

\section{CLOSE TIES}

Researchers at Nankai and Tianjin universities co-author more papers with each other than any other domestic partner. Top five domestic collaborators in 2014 are shown.

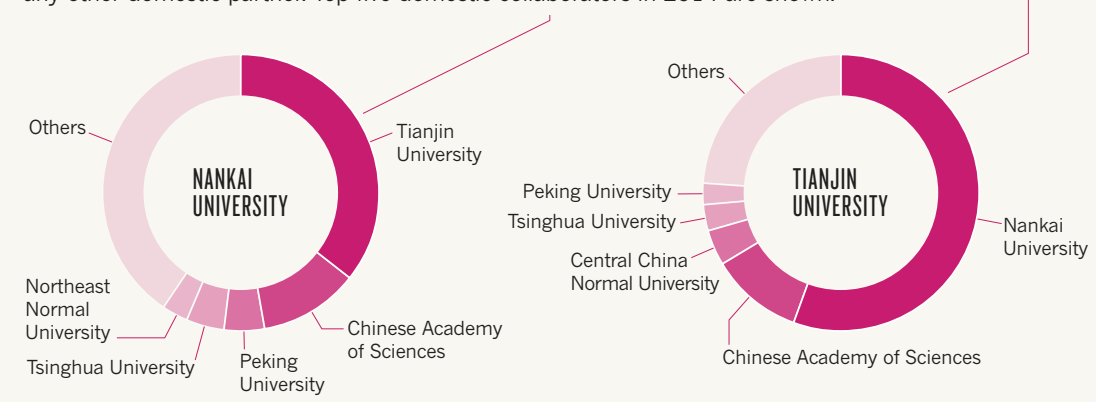

60

80
"Special collaboration grants to support travel and conferences are good, but only support the original ideas," Guo says.

\section{TIANJIN}

\section{$\rightarrow$ WFC rank China: 10 A $A C: 461$}

Tianjin has more universities in the index than Hong Kong and Hefei, although much of its basic research is conducted at two institutions - Nankai and Tianjin universities. These universities had collaboration scores of 254.3 and 163.9 in 2014; much larger than the combined figures of the remaining universities and institutes in this northern city, which neighbours Beijing.

Research at these universities is highly complementary, partly because of historical logistics. In 1952, in line with a Soviet model, the newly-founded People's Republic of China government transferred most of the science departments in Tianjin University (TJU) to Nankai while boosting TJU's engineering capacity. As a result, TJU's engineering research and application is strong, but its basic research is relatively weak. To counter this, the neighbouring universities formed a strong partnership in chemistry and physical science research.

In 2012, partially funded by the Ministry of Education and Tianjin municipal government,
TJU and Nankai jointly established the Tianjin Co-Innovation Center of Chemical Science and Engineering. "The centre has produced many of our co-authorships," says Nankai materials chemist, Yang Zhimou, who along with his team has authored several Nature Index papers.

Many TJU faculty members graduated from Nankai or vice versa and retain strong allegiances to their alma mater. This contributes to ongoing close collaboration, says Ma JunAn, a TJU Department of Chemistry professor who recently published in Organic Letters, a top chemistry journal in the Nature Index.

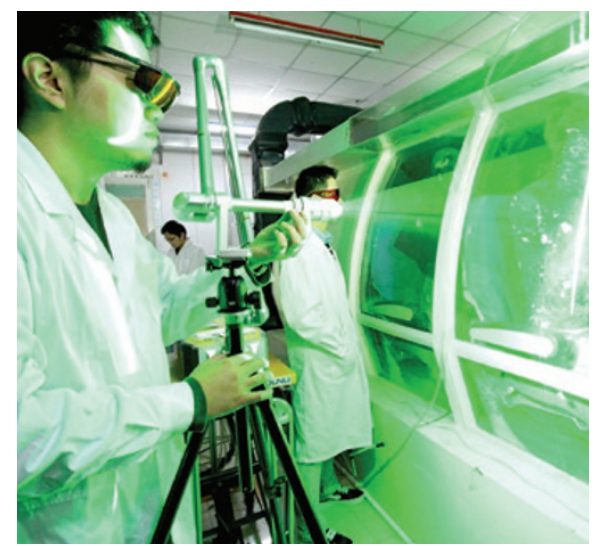

Tianjin University researchers explore airflow for the first China-developed passenger jet, the C919.
Nankai and TJU are Tianjin's largest collaborators, and in 2014, most frequently collaborated with each other (see 'Close ties'). These strong local links have been forged, according to Yang, as a "International result of relatively poor partners are crucial to explore our frontier studies." funding and a lack of equipment at Nankai and Tianjin universities. This situation has pushed researchers to exploit resources available locally.

But local partnerships do not thwart collaboration with other domestic and international partners. "Besides strong local partnership, we also have stable collaborations with CAS, CNRS [in France], RIKEN [in Japan] and the University of Texas [in the United States]. They are mutually supportive," Ma says.

The Nankai-TJU Co-innovation Center was established under policies of the ministries of education and of science and technology to encourage collaborations among Chinese research institutions. Initiated in 2011, so far nearly 100 co-innovation centres have been recognized and funded partially by the ministries. Other financial sources come from the universities themselves, local governments and industries, when a centre is industry-oriented. 